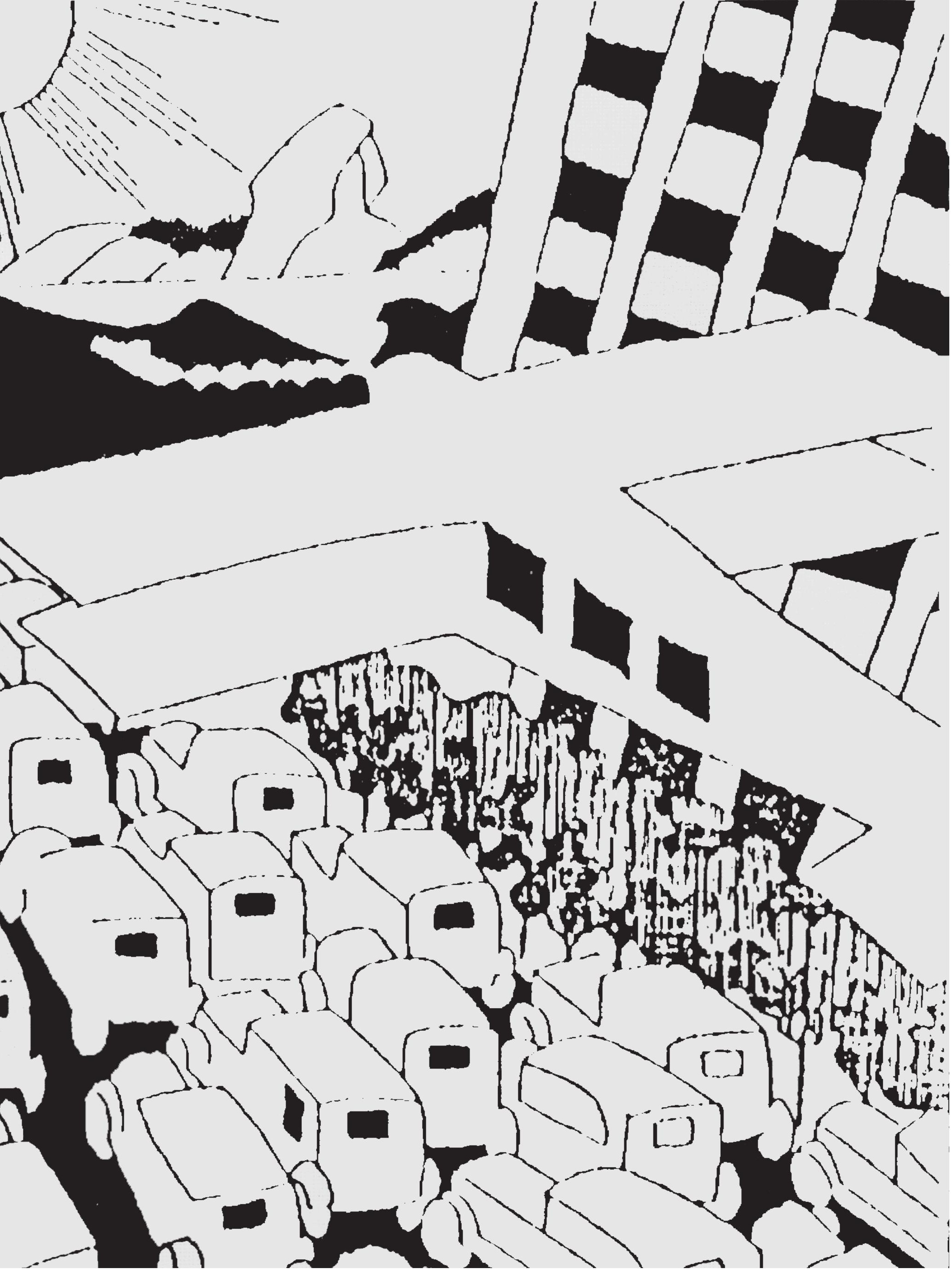




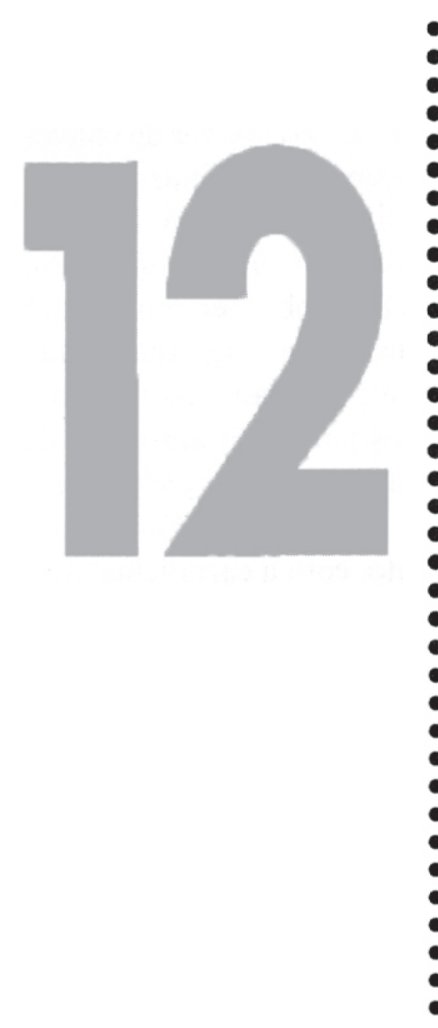

NICOLAU SEVCENKO

\section{Arte e crise cultural \\ nos anos 20: 0 repto \\ de Roberto Rodrigues}

"When the evening is spread out against the sky

Like a patient etherized upon a table"

(T. S. Eliot, Love Song of J. Affred Prufrock).

á momentos em que as sociedades perdem as palavras ou em que as palavras se tornam ocas de seus sentidos. Nesses momentos se tornam cruciais aquelas criaturas capazes de retraduzir as palavras em imagens, os poetas, ou aquelas que transformam as imagens em sentidos, os artistas plásticos. Em tais situações uma sociedade se encontra paralisada, conforme as palavras de T.S.Eliot, "At thestill point of the turning world" (Burnt Norton). Toda a poesia de Eliot ressoa essa circunstância, como gritos num silêncio sem eco. Nesses instantes de hesitação as convicções desvanecem, as referências se dissolvem, mas uma vez mais os homens recuam diante do pavor de ver a substância do mundona sua crueza, destituída doinvólucrode categoriasque a ameniza, homogeneiza e reduz ao metro de um entendimento 울 cifradoeconsagrado. "Human kind cannotbearverymuch reality" (idem). Portanto, diante do impraticável de acionar palavras vazias ou do intolerável de olhar o mundo sem a cortina espessa e translúcida dos códigos cerrados, a alternativa mais imediata é a ritualização da experiência direta como forma de condicionar o
NICOLAU SEVCENKO é professor de História da Cultura do Departamento de História da FFLCH-USP e autor de Orfeu Extático na Metrópole. São Paulo, Sociedade e Cultura nos Frementes Anos 20 (Companhia das Letras).
NA PÁGINA ANTERIOR E
NAS SEGUINTES,
ILUSTRAÇES DE ROBERTO RODRIGUES

- O contato com a obra de Roberto Rodrigues foi possível graças à exposiçăo "Roberto Rodrigues 1906-1929", realizada no A. S. Studio, em Sáo Paulo, de 10-11 a 11-12 de 1993. A exposição foi montada sob a curadoria de Estela Sahm, a quem agradeço aqui a generosa colaboraçăo e as valiosas in. formaçōes prestadas. 
potencial destrutivo da ação pura e sem limites. $\mathrm{O}$ gesto assim contido pela sagração da ameaça mais iminente se torna a raiz de que haverá de brotar a nova formalização dos sentido. Eliot descreve essa metamorfose do terror para a ordem desta forma:

"Last season's fruit is eaten

And the fullfed beast shall kick the

lempty pail.

For last year's words belong to last year's [language

And next year's words await another [voice"

\section{(Little Gidding).}

A obra de Eliot ficou para sempre umbilicalmente ligada à crise traumática singular da Grande Guerra. Toda uma civilização foi enterrada sob seus escombros fumegantes, dispensada às pressas e sem remordimentos nostálgicos pela despedida solene do soldado Robert Graves no seu Goodbye to all that e logo esquecida pela saudação entusiástica de seu colega Ezra Pound, na palavra de ordem do pós-guerra, "Save the New!". Diferentemente de ambos, porém, Eliot nem dispensou o legado em destroços dos milênios, nem celebrou a era das tecnologias massificantes. Sempre lhe pareceu claro que a descontinuidade aberta no presente não abolia o caráter intrinsecamente contaminante do tempo. Seu sentido de relatividade histórica a rigor incomodava as novas gerações e foi o principal motivo de ele permanecer na contracorrente do modernismo. Enquanto os jovens clamavam pelo novo puro e pelo moderno absoluto, o jovem Eliot ponderava com aguda percepção moderna:

"Time present and time past

Are both perhaps present in time future And time future contained in time past" (Burnt Norton).

Isso estava longe de significar uma negação da singularidade do seu momento. Poucos poetas puderam traduzir o impacto $\mathrm{psi}$ cológico e cultural da Grande Guerra como Eliot o fez no seu The Hollow Men ("We are the hollow men/ We are the stuffed men Leaning together" e que termina com os versos "This is the way the world ends Not with a bang but a whimper"). Mas a maneira de encararo mundodeixado pela guerra era muito diferente dentre os demais colegas de sua geração artística. Os cartazes de convocação para o alistamento militar logo no início do conflito traziam a célebre imprecação "What did you do in the Great War, daddy?". A idéia óbvia era impregnar os recrutas potenciais da vergonha de que não tivessem compartilhado do último $\mathrm{e}$ maior de todos os lances de heroísmo da humanidade, aquela que H. G. Wells proclamara The War That Will End War.Jápara o fim do confronto, com a carnificina atingindo proporções inimagináveis, não eram mais os pais mas os filhos que eram despedaçados em massa sob o fogo das metralhadoras, obuses e lança-chamas. Foi para esses últimos que Rudyard Kipling compôs seu epitáfio à juventude sacrificada: "If any question why we died/Tell them, because our fathers lied".

Para essa nova geração, a palavra passado era sinônimo de abominação, hipocrisia e danação. $\mathrm{O}$ tempo se havia rompido num imenso vórtice, ao redor do qual todo solo firme erapântanopestilento. Sóo mergulho na voragem ainda sem nome das novas energias liberadas pelo cataclisma salvaria. Eis como Stefan Zweig descreveu a atmosfera febril do pós-guerra, na posição de testemunha pessoal do turbilhão dissolvente:

"Que época bárbara, anárquica e inverossímil (...). Foi uma época de êxtase entusiástico e fraudes ousadas, foi um misto de sofreguidão e de fanatismo. Tudo o que era extravagante e inverificável teve então a sua época áurea: teosofia, ocultismo, espiritismo, sonambulismo, antroposofia, quiromancia, grafologia, doutrinas hindus de yoguese misticismo paracélsico. Tudo o que prometia excitações máximas, superiores às até então conhecidas, toda espécie de veneno inebriante, morfina, cocaína e heroína tiveram grande saída; nas peças teatrais o incesto e o parricídio, na política o comunismo e o fascismo constituíam a temática extrema e a única desejada; toda espécie de normalidade e moderação, ao contrário, era absolutamente condenada (...). Creio que conheço bastante a fundo a História; ao que eu saiba, porém, ela nunca produziu uma época de semelhante loucura em pro- 
porções tão gigantescas. Todos os valores e não só os materiais estavam altera$\operatorname{dos}(\ldots) "$.

Foi sob essa atmosfera tensa e soturna, também, que Yeats pressagiou o nascimento de forças obscuras que haveriam de se materializar tanto na superfície iluminada das ruas, quanto nas profundezas insondáveis das almas, no seu The Second Coming:

"The darkness drops again; but now I [know

That twenty centuries of stony sleep

Were vexed to nightmare by a rocking [cradle,

And what rough beast, its hour come [round at last,

Slouches towards Bethlehem to be [born?".

Ao invés de se empenhar na busca de alguma alternativa de fuga ao desespero ou resignar-se ao imperativo dos novos fluxos coordenados de massas e energias, Eliot, nesse contexto, opera comoum contraponto capaz de reverberar os efeitos de fragmentaçãoe aceleração experimentados na transformação do cotidiano, sem contudo abrir mão do distanciamento reflexivo, que lhe permitia confrontar a nova situação com a sabedoria plástica da imaginação mítica anterior aos reducionismos racionais $\mathrm{e}$ tecnológicos. É interessante nesse sentido comparar sua atitude com a de outro representante exponencial desse momento crítico, o poeta e erudito francês Paul Valéry. No seu famoso diálogo A Alma e a Dança, incorporando significativamente o papel de Sócrates, pedra angular da metafísica racionalista, Valéry manifesta sua convicção sobre o efeito potencializador de uma íntima fusão do domínio consciente sob os ritmos sincopados das novas tecnologias mecânicas, metamorfoseados no frenesi das danças modernas:

"Eu mesmo me sinto invadido de energias extraordinárias; eu as sinto irradiarem de mim, que ignorava conter tais virtualidades. Num mundo sonoro, retumbante e ritmado, a intensa festa do corpo diante da nossa alma oferece alegria e luz; qualquer coisa é solene, qualquer coisa é simples, tudo é vivo e forte, tudo é possível de um outro modo, tudo pode começar indefinidamente. Nada resiste à alternância das batidas fracas $\mathrm{e}$ fortes. Bate! (...) Um corpo com a sua simples energia, num ato, é forte o suficiente para alterar mais profundamente a natureza das coisas, do que o intelecto com seus sonhos e especulações jamais alcançará".

Aos olhos de Eliot, porém, essa precipitada dissolução da alma sob os solavancos de um mundo aparelhado pela engenharia e o planejamento de fluxos, celebrado no êxtase dos ritmos irradiantes, pareceria uma rendição a uma realidade sem seiva nem espessura e a um delírio de grandeza cego e abortivo. Ele sequer se ocupa de apontar a dimensão trágica desse projeto turvo de aprendizes de feiticeiro. Seu interesse é outro, mais pessoal e concreto: mergulhar nas sombras da solidão e da irremediável incomunicabilidade que tornou o mundo das massas, das energias colossais e dos ritmos eróticos numa terra desolada onde a respiração sufoca, os sonhos enloquecem e os animais não falam mais. Todo seu esforçoé para reencontrar os limites e as fronteiras, onde quer que estejam esquecidos e abandonados, e recomeçar dali uma peregrinação à condição de um ser perdido que tateia em busca do que existe por detrás das palavras. Nessa nova odisséia,

\section{"Each venture \\ Is anew beginning, a raidin the inarticulate With shabby equipment always [deteriorating \\ In the general mess of imprecision of [feeling" \\ (East Coker).}

Num dos desenhos da série "Senhorita 1950", realizados em 1927 e destinados à revista Paratodos, o artista e ilustrador Roberto Rodrigues compôs uma imagem que é ao mesmo tempo mirífica e perturbadora,comoera característicodoseu trabalho $\left({ }^{*}\right)$. Uma dançarina se apresenta nua, exceto por uma aura de plumas às costas e uma delicada folha de parreira que, saindo de seu umbigo, recobre superficialmente seu sexo (Figura 1). A imagem é de grande impacto por conta de um efeito to- 
AO LADO,

PASSAGENS A UM PASSANTE" (1926); NA OUTRA PAGINA. "MÁOS POSTAS (1929), REVISTA PARATODOS

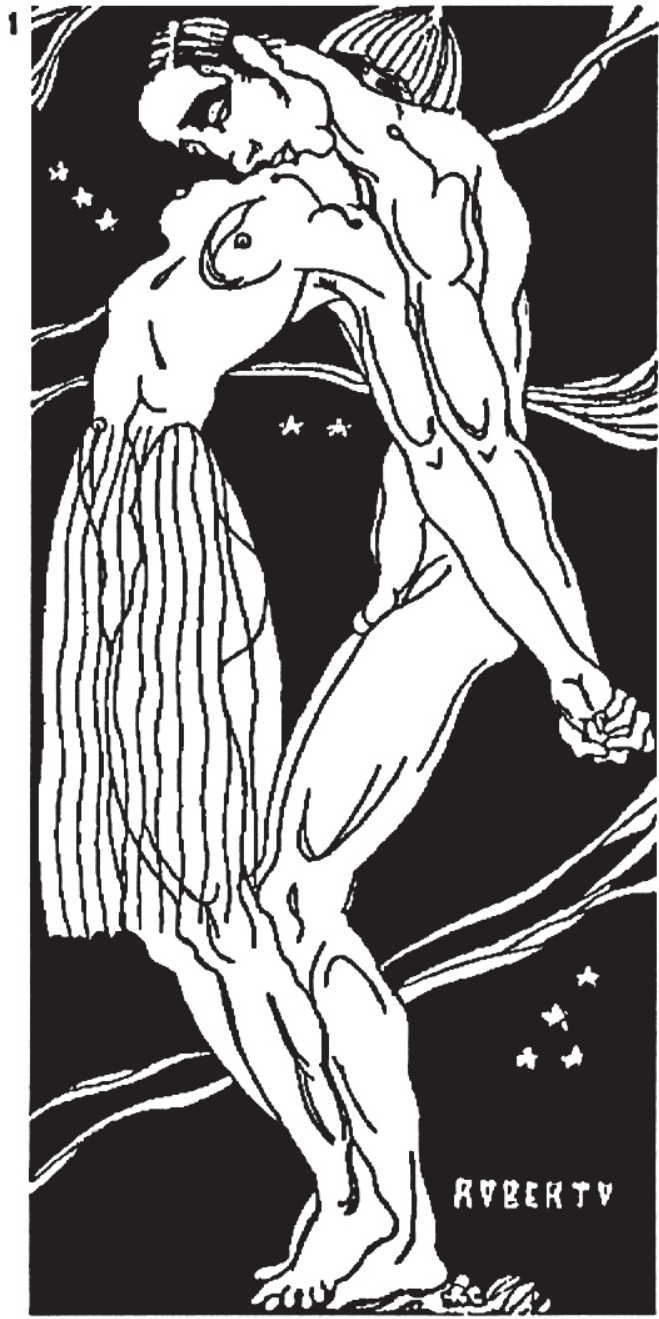

talmente moderno e ainda muito recente no período, o que multiplicava o teor chocante do desenho. O que toca não é a simples nudez da bailarina, mas o fato de que ela a expõe diretamente sob um poderoso foco de luz, procedente de um holofote de alta intensidade, que irradia e amplifica a força erótica da sua figura contra o escuro do ambiente, ao mesmo tempo em que revela com a máxima nitidez todos os menores detalhes de sua carne, de seus músculos, das formas de seu corpo e da textura de sua pele. A sugestão simbólica da folha de uva evoca a figura mítica da Eva. Nesse caso, porém, não se trata mais da Eva natural do Velho Testamento, mãe de todos os homens, nem tampouco a Eva da luz homogênea e ponderada do Renascimento. É uma Eva da tecnologia, exposta com a minúcia de detalhes de um paciente na mesa cirúrgica, sob o impacto dissecador de mil watts de luz elétrica.

A platéia, às escuras e anônima, acom- panha exaltada as evoluções da dançarina, batendopalmas e acentuandoo tempo forte do ritmo sincopado. Público e bailarina se tornam uma entidade única, vibrando em uníssono, palmas e pés coincidindo com os requebrados da dança, olhos hipnotizados pela massailuminada,sinuosae volátil,numa perfeita comunhãododesejoporejante com a entrega descomedida. Um segundo foco luminoso, mais finoe concentrado, parte do fundo do palco e, atingindo um globo recoberto de pequeninos espelhos, projeta um salpicado de fagulhas luminosas sobre a massa escura do auditório, reforçando o ar de fantasmagoria, permitindo aos espectadores compartilhar fagulhas da bênção luminosa em cascatas contínuase fazendo tudo que é sólido e estável elevar-se e dançar, num turbilhão que a tudo e a todos arrasta para o mesmo clímax de excitação e fusão numa totalidade energética integral.

A linguagem dodesenhose revelou altamente propícia para articular visualmente esse novo mundo, construído pelo contraste potencializador do foco luminoso intenso contra a escuridão total. Uma lição que foi aprendida em definitivo com a criação dos poderosos holofotes, destinados a caçar pelos céus aviões em missões noturnas durante a guerra. Mas que já tivera seu pioneiro uso artístico com o desenvolvimento do teatro de palco vazio do iluminador francosuíço Adolphe Appia, que estabelecia climas cênicos pela modulação alternada ou conjunta de focos, intensidades e tonalidades de luz de arrebatante impacto psicológico, utilizados por Pirandello, Cocteau, Beckett, Ionesco, dentre outros. Essa descoberta continuamente aprofundada do poder extraordinário que tem a luz intensa sobre o subconsciente humano culminaria com a elaboração, por Albert Speer, das colossais arquiteturas de luz a céu aberto, utilizadas para criar o cenário surreal e megalomaníaco dos festivais noturnos do Partido Nacional Socialista em Nuremberg, sob a coordenação do mestre-de-cerimônias Joseph Goebbels.

O desenho, melhor do que as outras linguagens, consegue, pelo efeito do traço fino sobre o branco do papel, evocar a experiência extrema dos corpos intensamente iluminados contra a mancha negra homogênea da escuridão. Roberto Rodrigues tinha uma percepção aguçada dessa virtualidade pro- 
digiosa da sua arte. Há no seu traço nítidas reminiscências dos estilo art noveau, sensíveis na propensão ao alongamento sinuoso das linhas, na expansão irradiante dosfeixes decorativos ou na simetria interveniente das composições. Mas o art noveau era uma linguagem ainda em correspondência com a luzhomogênea da arte pós-renascentista ou, quando muito, com sua decantação climática pelos impressionistas e fauves. Sua busca de dinamismo, ritmo, agilidade, serialidade decorativa e organicidade integrada, essenciais para a apresentação de seus temas favoritos, a alteração da experiência cotidiana sob o impacto das novas tecnologias, o levou a assimilar o palpitante vocabulário visual da art déco.

Tomando essas duas linguagens como patrimônio comum, Roberto Rodrigues faria delas um uso seletivo, utilizandoelementos típicos de seus repertórios para fins que lhe eram peculiares. É aliás notável sua capacidade tanto de incorporar diversas tendências características do desenho no pósguerra - fato que a condição periférica da América Latina e Brasil favorecia, ao importarinformações acabadassem os respectivos contextos de criação -, quanto de dispor delas com uma desenvoltura que seria impossível em seus ambientes de origem, exatamente pelas mesmas razões. Nesse sentido, Roberto é um artista de grande originalidade e densidade estilística. Por exemplo, é patente sua informação, direta ou indireta, pouco importa, sobre as características artísticas que assumiram o desenho e a gravura alemã do pós-guerra no âmbito da corrente denominada genericamente de nova-objetividade ou nova-sobriedade (Neue Sachlichkeit). Derivam daí a crueza do tratamento, a economia de recursos expressivos, o despojamento das imagens, a temática provocativa, a frieza e desprendimento com que expunha os mais controvertidos e explosivos atentados à moral vigente, sem a preocupação de temperá-los com ponderações éticas de qualquer espécie. Sua ênfase sobre a materialidade, carnalidade, sensualidade, voluptuosidade dos corpos jovens, expostos e oferecidos no primeiro plano e à plena luz à fruição voyeurista, sugerindo a abolição de normas limitadoras de uma sexualidade franca e compulsiva, evoca o traço lascivo, nervosoe a figuração abertamente obscena dos dese- nhos de Jean Cocteau. É toda a crise civilizacional do pós-guerra que se vê palpitando nos trabalhos de Roberto Rodrigues, elaborados com um complexo e refinado cabedal artístico, em sintonia com o clima cultural de seu tempo.

Há um desenho seu que bem poderia ser um auto-retrato artístico e intelectual. Trata-se da ilustração para o conto de Paulo Fernando "A Carta que Eu Não Escrevi", publicado pela Paratodos (Figura 2). Nele uma figura jovem, definida por uma silhueta em traço leve, preciso e retilíneo - acentuando o talhe refinado e aristocrático do rapaz-,reluta, apoiado nocriado-mudo, entre a pena e o papel em branco. À sua frente, na cama em primeiro plano, uma bandeja com um pote e taça de café, um caderno de notas, um maço de cigarros cheio, uma caixa de fósforos e uma porção de cigarros soltos que

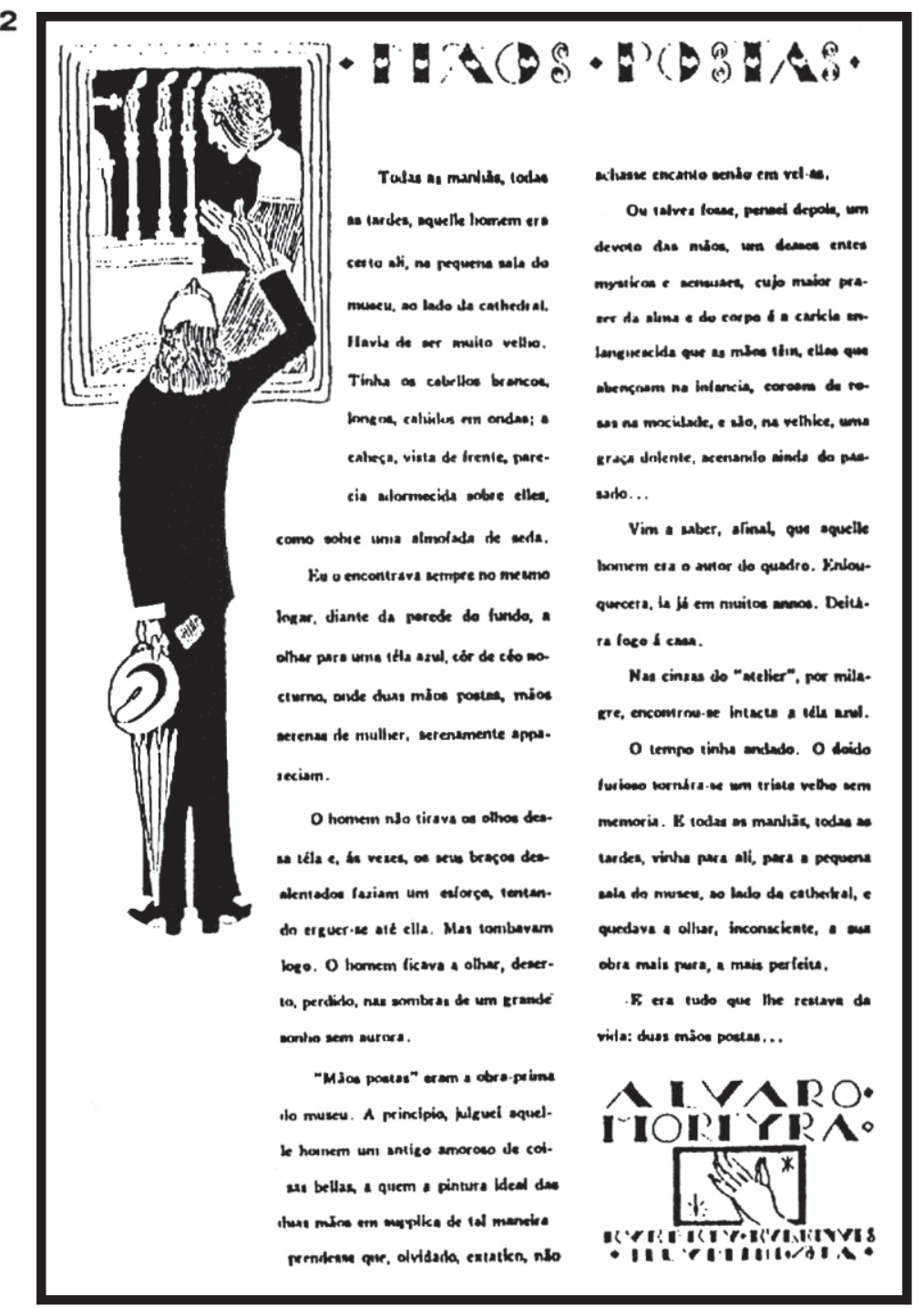




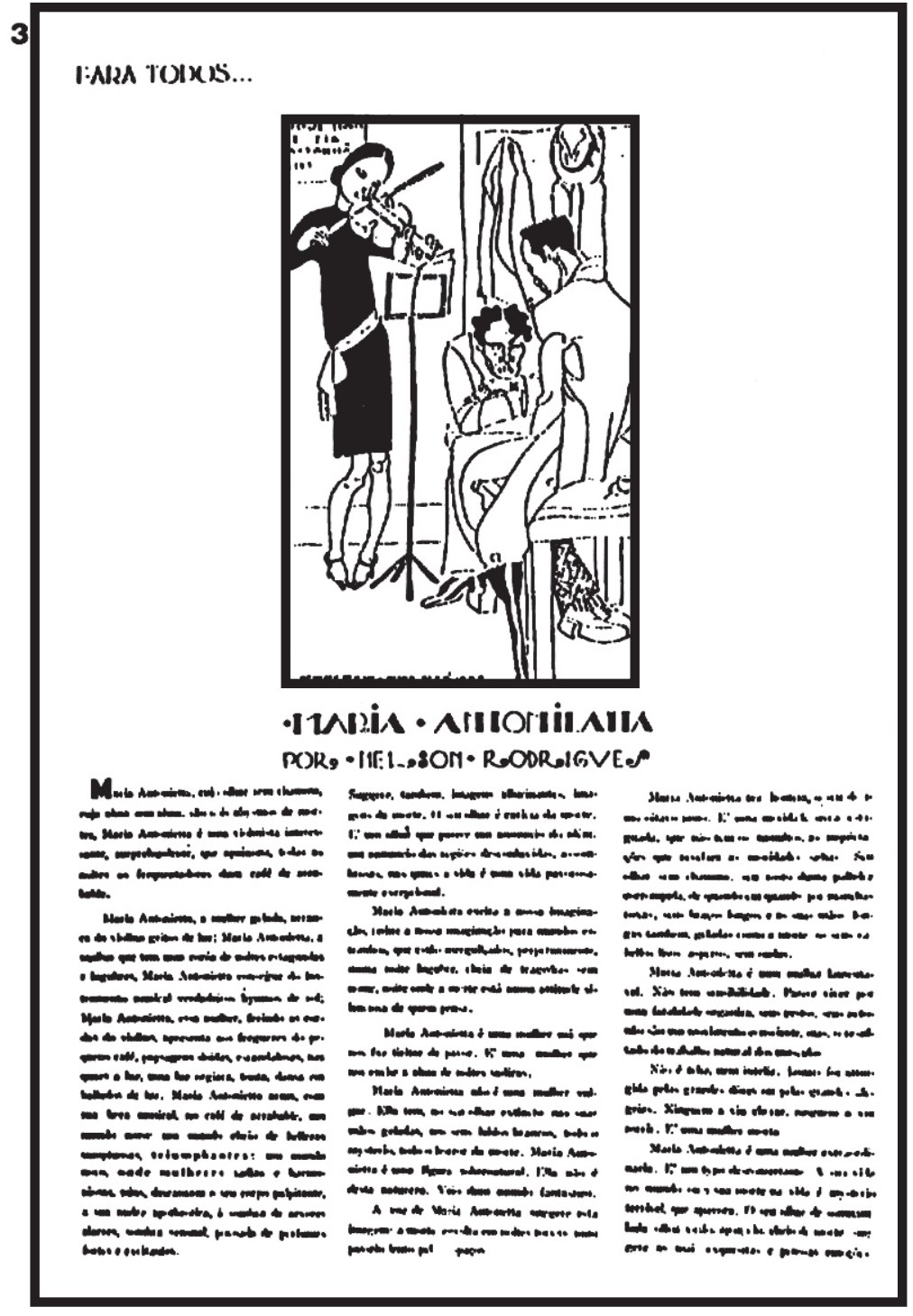

ACIMA, "MARIA ANTONIETA" (1929), REVISTA PARATODOS: NA PAGINA AO LADO, "VICTORIA" (1920), PARA A MESMA REVISTA das novas energias: os estimulantes do cotidiano acelerado, café e cigarros abundantes. Dois tempos, dois estilos de vida e dois quadros sociopolíticos em confronto histórico, a própria tensão crítica do final da Primeira República no Brasil. Ao meio, entre os dois extremos e relutante, ojovem artista refinado e paralisado no impasse cultural.

Noutro desenho, ilustração para o conto "Maria Antonietta" de Nelson Rodrigues, também na Paratodos, mais uma situação emblemática (Figura3). No fundo toca uma moça violinista, de nítido talhe modiglianesco, magreza, sinuosidade e projeção longilínea, rosto, olhos e cabelos ligeiramente achinesados, absorta e totalmente entregue ao instrumento e à música. No primeiro plano, dois rapazes, um branco sentado e debruçado sobre a mesa, outro negro e sentado sobre ela, por trás do qual, em destaque, uma taça de café. O negro tem seus traços étnicos representados em rigorosa geometria art déco. O café de subúrbio é um ambiente moderno e pretensioso: subúrbios em princípio só deveriam ter bares sórdidos para venda de aguardente $\mathrm{e}$ freges para urgências sexuais. E jamais, naturalmente, seriam motivo de interesse artístico. Jovens refinadas e com educação musical não são supostas tocar por dinheiro e seria indizívelque se apresentassemsozinhasnum café de subúrbio. Negros não entram em cafés e seria caso de linchamento se cometessem o acinte de se sentarem sobre a mesa onde quer que fosse. Que espécie de imagem é essa portanto? Um panfleto revolucionário? Não, os próprios personagens tratam de desmobilizar qualquer leitura panfletária. Não se olham, não se comunicam, não assumem outra atitude senão a da entrega à clausura da mais irremissível solidão, voluntariamente assumida e articulada com projetos pessoais díspares, insinuados pela própria diversidade do tratamento estilístico para cada um. Vivem todos numa utopia amoral e dispersiva, onde a música e a arte são toxinas e não nutrientes do espírito e onde a política é a democracia do desafio e da ousadia, não a rotina da submissão e alinhamento.

Mas a cena não raro é muito mais brutal que isso. Num mundo acionado pelo primado dos instintos e, em especial, dos instintos açulados pelas substâncias tóxicas, egoísmo, agressividade, sexualidade e ardor extático 
são as energias básicas, que se confundem, combinam e confrontam. Em "Ela Sufocou um Grito", da mesmaséria "Senhorita 1950" da Paratodos, a arte de Roberto Rodrigues se mostra no seu vigor mais espontâneo (Figura 4). Num ambiente chinês, um rapaz artificiosamente elegante, de torso nu e contraído, golpeia a navalhadas uma moça seminua, que tenta em vão proteger o rosto cobrindo-o com as mãos, recolhida sobre um sofá. A ambiência chinesa, tão improvável quanto exótica para o Rio de Janeiro, evoca as drogas. O torso nu do rapaz domina completamente o espaço e a dinâmica da composição. Linhas quebradas e curvas enxutas denotam a musculatura trabalhada pelo esforço atlético, exuberante, viril e implacável. Os olhos cerrados do homem da navalha, que Roberto acentua com uma apresentação em costura cerrada, mais do que os efeitos da intoxicação, indicam o ímpeto subconsciente que comanda o ataque à moça, num misto de impulsos sexuais e agressivos. O gesto defensivo da garota surge quase como um complemento coreográfico da violência sexualizada e ritualizada que os dois representam. O tratamento visual de seu corpo todo em traços curvilíneos suaves se contrapõe com odo rapaz, acentuandoseu papel paciente e receptivo. Ambas as atitudes no exagero e dramaticidade dos gestos sugerem uma dança, enfatizada e marcada pela regularidade rítmica dos elementos decorativos da composição. Como um tango visual.

Na mesma linha vãoos primorosos desenhos da série "Senhorita Sempre a Mesma" (Paratodos)(Figura 4).Com a diferença que aqui os papéisse invertemeé a mulherquem tem a iniciativa. A Senhorita é vista como o gatilho que deflagra a febre do desejo. Cabe a ela contudo decidir quando apertar o gatilho e para quem apontar a arma. Ela não usa a arma do sexo só para seu gozo, mas também para exterminar tabus e preconceitos que a cerceiam e para seduzir e escravizar pelo desejo aqueles que quer fazer instrumentos da sua vontade soberana. Seu sexo liberto instaura o anarquismo dos instintos. Sua preferência é pela acumulação dos potenciais ameaçadores: ela submete atletas, agressivos, renegados, imorais, devassos, perversose egocêntricos. Seu gozo tem uma direção que aponta para o poder econômi$\mathrm{co}$, o sucesso social e a autocracia pulsional.
Nãoé portanto do ser feminino que se trata aqui. Roberto se refere à transformação política e cultural - inclusive pela via econômica da publicidade e da indústria do entretenimento - do sexo numa das energias motivacionais ou toxinas estimulantes, agenciadas no contexto das novas tecnologias, para produzir efeitos de intensificação de disposições, dissolução de limites e convenções, além da exacerbação de comportamentos e aguçamento de expectativas. A encenação do sexo liberto se torna assim um açoite que espicaça a vontade pela inflamação do desejo, não sendo pois surpreendente aênfase sadomasoquista comque Roberto insiste em representá-lo.

Uma das suas composições mais elegantes tem como tema, pura e simplesmente, "OElogioda Cocaína"(Paratodos) (Figura 5). O aspecto hierático da composição é

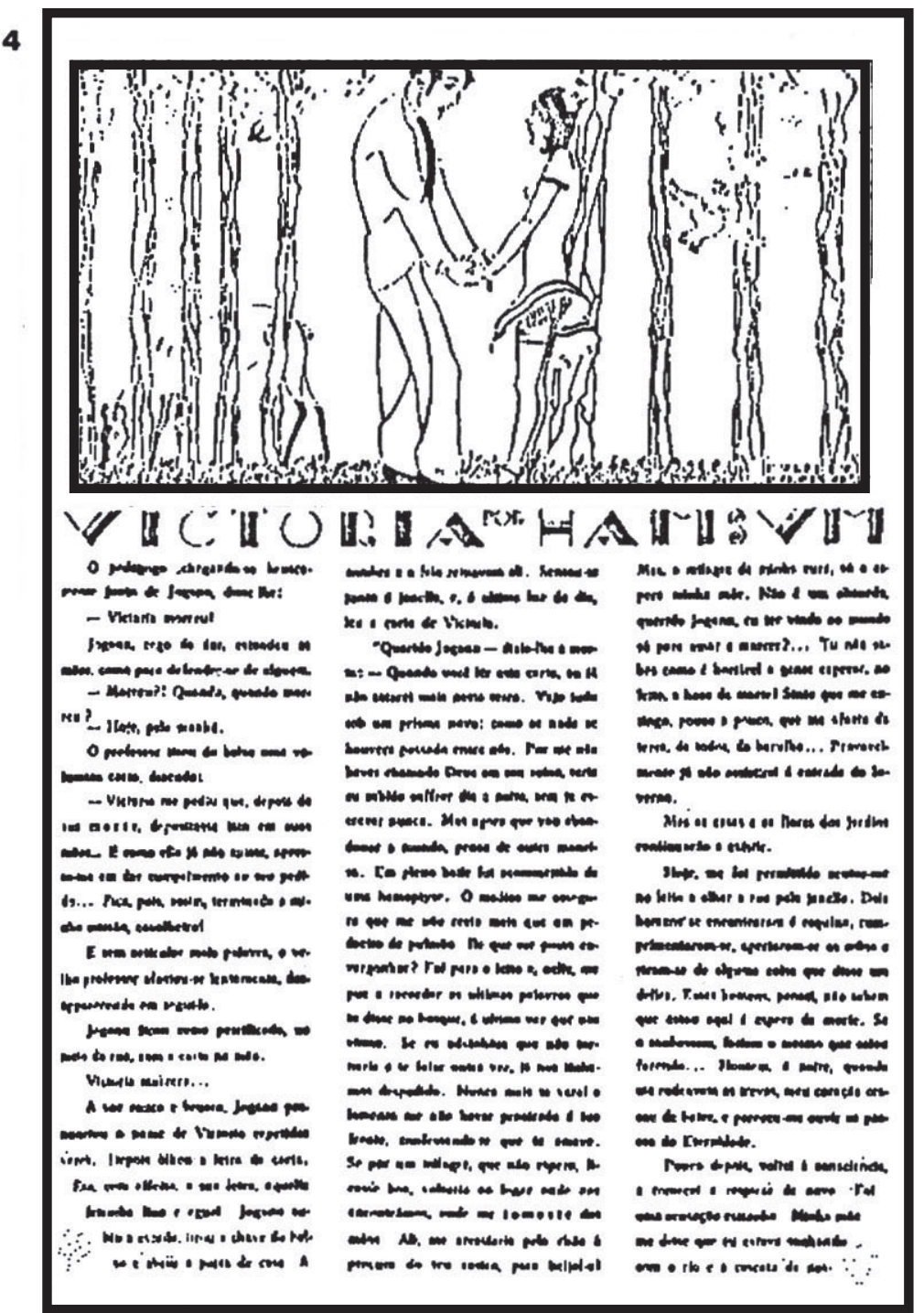




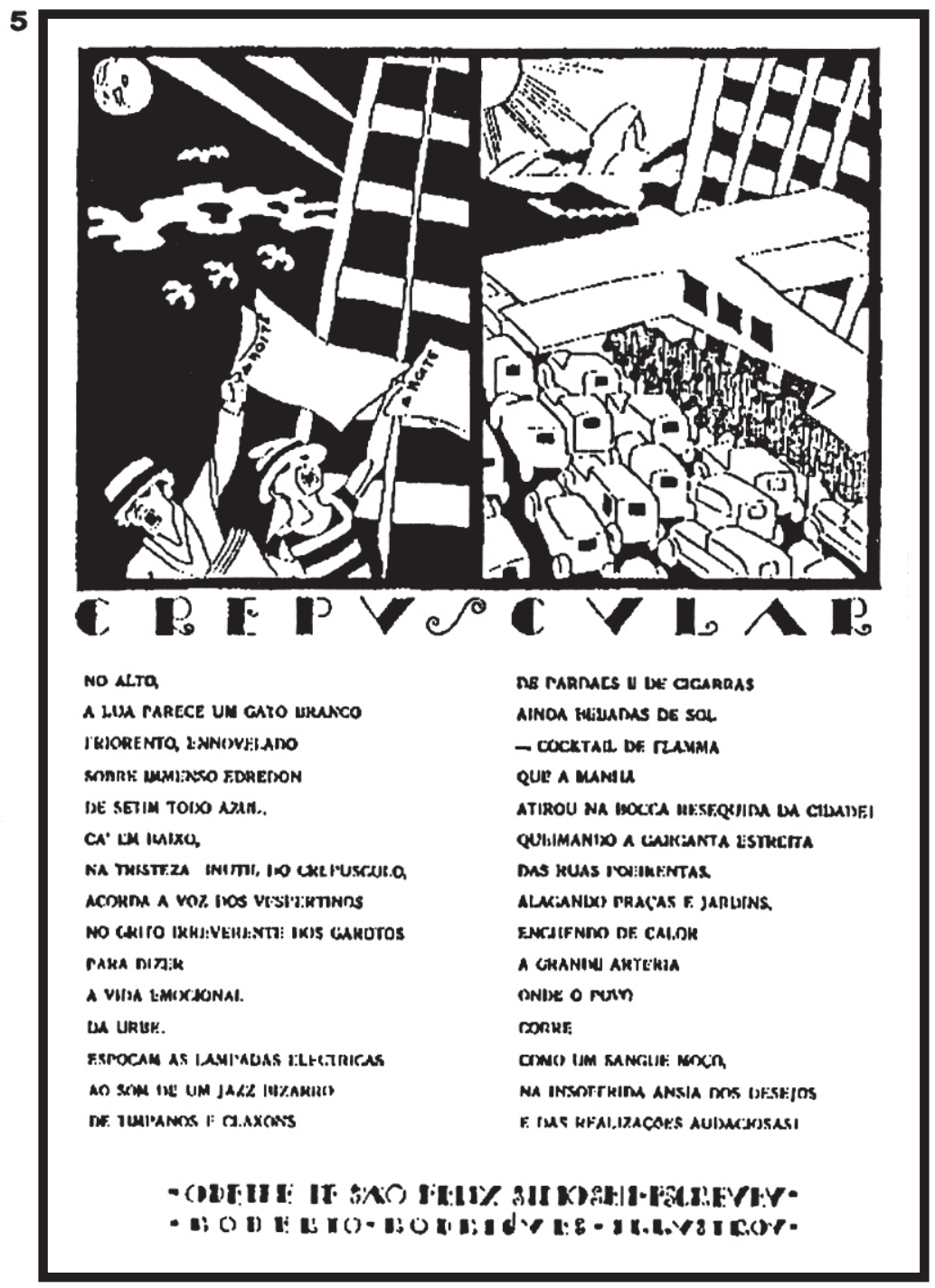

"CREPUSCULAR" (S/D), REVISTA PARATODOS; NA PÁGINA AO LADO, "O ÚLTIMO ROMÁNTICO (1928), MESMA

(1928), MESMA
PUBLICAÇÃO mesmo desses poderes materiais. É por isso intimamente associada ao sexo e suas derivações gratificantes, na seminudeze conluio voluptuoso dos personagens. As estrelinhas e os pássaros que acentuam a elegância decorativa da composição reforçam também as conotações religiosas (o universo, o espírito santo, os querubins barrocos), além de ironicamente representarem os sintomas do entorpecimento da consciência e da percepção. Há mesmo uma monstruosa correspondência entre os rostos colados das três figuras, em êxtase de torpor e gozo, e os seus corpos, cada qual nos traços marcantes de seus músculos e carnes, sugerem gigantescas carantonhas horrivelmente distorcidas. As tangas sumárias que cobrem seus sexos tanto suscitam respostas sensuais quanto sugerem o martírio. As pedras e o mar calmo abaixo, mais que o infinito, para essas figuras urbanóides, são só o vazio estéril e tedioso de que querem desesperadamente fugir.

As anotações e o registrosociaissãoigualmente expressivos nabreve obra de Roberto Rodrigues. Sua experiência da formalização social da violência não veio, no Brasil, da guerra longínqua, mas da confrontação de grupos sociais, aberta, difusa e patente por toda parte no país. A criminalidade brutal dodia-a-dia, a prevalência da lei do cão, tanto pontua a rotina elegante da burguesia local (como se verifica na série da "Senhorita 1950"), como a azáfama da classe média (conforme exposto no jornal de crimes e escândalos Crítica, criado por seu pai e ilustrado por Roberto), a luta insana pela sobrevivência nosubúrbio(comose viuno "Ela Sufocou um Grito")ou ainda os rincões mais remotos do país (como fixado na tétrica imagem de "O Cangaceiro") (Figura 6). Nessa última, de complexa feitura e refinado acabamento, não há quaisquer possíveis glamurizações do banditismo social, que já se tornara uma convenção artística, apenas a crua exposição da sádica materialização da violência como poder em estado puro. Roberto flagrava o instante mesmo em que os conteúdos pulsionais mais recônditos afloravam nas faces tanto dos executores quanto das vítimas, expondo o crime não apenas como fato social, mas como a evidência de uma recodificação da realidade por energias subconscientes, medonhas demais para serem admitidas, irracionais por completo, portanto inacessíveis à reflexão, 


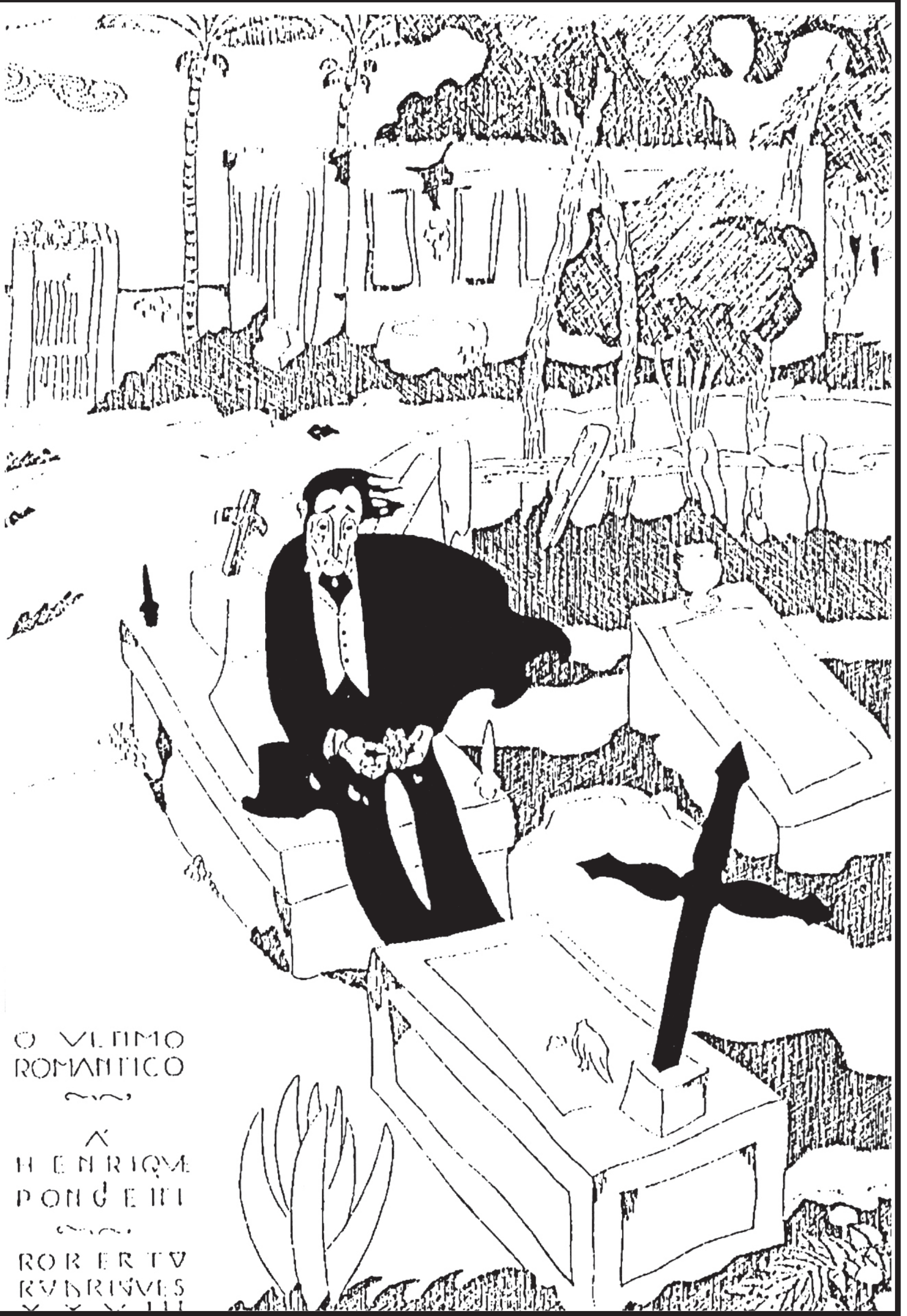


ABAIXO, :O BEIJO DO DO NORTISTA"

REVISTA PARATODOS SULISTAE O BEIJO

e no entanto fundamentais na estruturação da nova ordem, a ponto em que um artista honesto e arguto não poderia deixar de alarmar seus contemporâneos com elas.

Nesse seu mundo de paradoxos, valores autênticos pareciam sempre só existir no passado, como reminiscência, projeção ou sonho. É o que se vê em imagens de um lirismo pungente como "Saudade" ou, mais fortemente, em "O Último Romântico" (Figura 8). Apesar do tema, nesta última, se Roberto Rodrigues adota convenções da gramática romântica na sua composição, ela diz coisa totalmente diversa do romantismo convencional. $\mathrm{O}$ ar patético da figura o é menos em virtude da dor pessoal que a aflige do que em relação ao observador contemporâneo da cena, para quem aquela criatura exótica e fora de contexto parece ridiculamente prostrada no fracasso de um tempo que se esgotou como potencial e só pode existir agora como uma terra da carochinha. Por outrolado, na ilus-

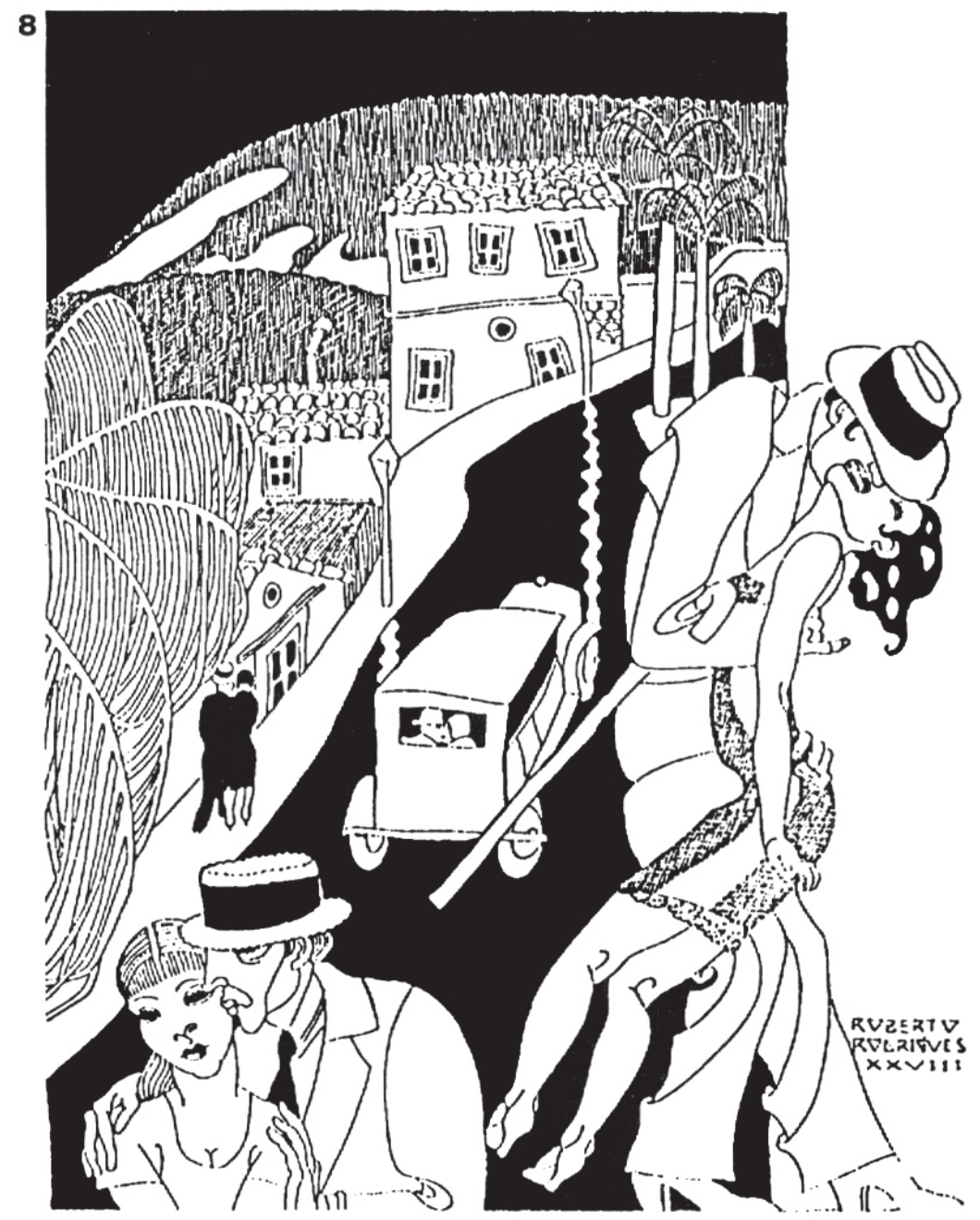

tração ao poema "Crepuscular", de Odette de São Félix Simonsen, Roberto faz cintilarem virtualidades desse novo mundo, que são o reverso de sua dimensão maldita (Figura 9). Em duas imagens simultâneas ele resume a latência promissora da realidade em fermentação. Numa, dois garotos pobres oferecem jornais noturnos em frente a um edifício, que irradia focos de luz em direção ao céu. Noutra, um fluxo de carros desfila em frente a um edifício (possivelmente o mesmo), sobrevoados por um aeroplano em vôo rasante, em plena luz do sol, o morro do Corcovado ao fundo. A enorme energia material acumulada durante o dia pela força inaudita dos maquinismos tecnológicos reverte à noite numa onda de estímulos simbólicos e sensoriais que retroalimentam o sistema e expandem o alcance de seus benefícios sociais. Numa das imagens a energia do sol é consumida e se soma ao cabedal multiplicativo das energias humanas e mecânicas. Noutra, é da terra que parte a luz artificialmente construída, que irradia tanto os céus quanto os feitos dos homens, suas expectativas e projetos futuros. É decisivo notar que nessas raras imagens de esperança, as duas únicas figuras humanas que aparecem são duas crianças pobres, frontalmente iluminadas por um gigantesco jorro de energia elétrica.

Tanto sua dimensão lucidamente crítica quanto seu impulso mais otimista aparecem na fusão genial de linguagens que Roberto Rodrigues alcançou nas ilustrações de capa da revista $J a z z$, que ele fundou com seu irmão Milton em 1927 (Figura 10). Ali estão vivos e pulsantes, em sintaxes linear e cromática irresistíveis nos seus apelos rítmicos e sensoriais, suas percepções aguçadas sobre a sexualidade, a nova economia pulsional, as intensificações eletromecânicas, o potencial instintivo da violência e o apelo libertador do entusiasmo construtivo. Jazz é ao mesmo tempo o que há, o que poderá haver e o que é preciso aprender a desafiar, fora e dentro de nós mesmos. Jazz é um lampejo de dor e desejo. Jazz é o futuro prenhe do passado abalando o presente moroso, à espera de um contra-ataque à altura do desafio. Onde estará perdida a luva de Roberto Rodrigues para que nós a recolhamos? Quem escolhe as armas nesse tempo das gerações? 

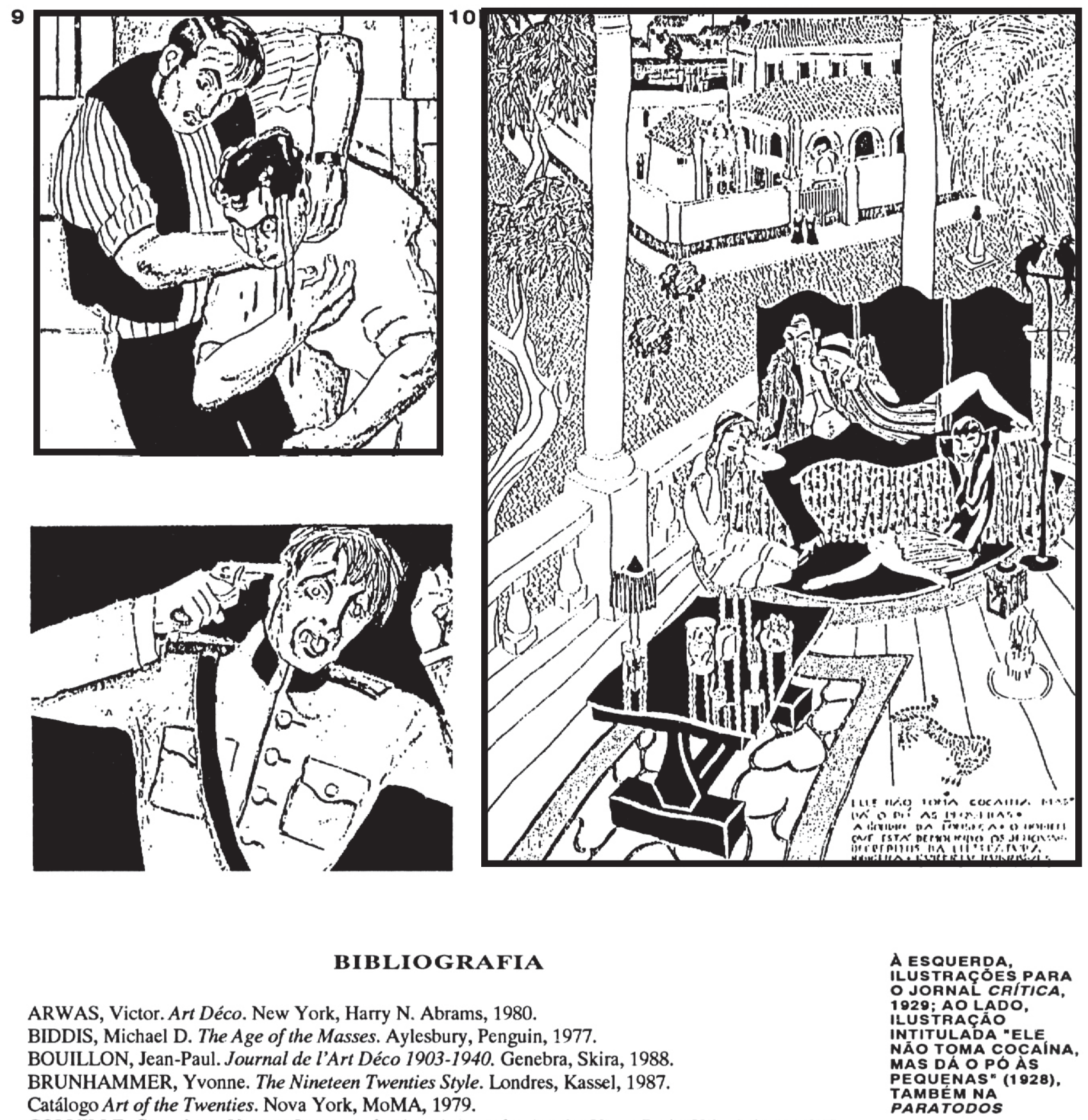

ARWAS, Victor. Art Déco. New York, Harry N. Abrams, 1980.

BIDDIS, Michael D. The Age of the Masses. Aylesbury, Penguin, 1977.

BOUILLON, Jean-Paul. Journal de l'Art Déco 1903-1940. Genebra, Skira, 1988.

BRUNHAMMER, Yvonne. The Nineteen Twenties Style. Londres, Kassel, 1987.

Catálogo Art of the Twenties. Nova York, MoMA, 1979.

COLVILLE, Georgiana. Vers un Langage des Arts Autour des Années Vingt. Paris, Klincksieck, 1977.

ELIOT, T. S. Selected Poems. Londres, Faber and Faber, 1990.

MORDDEN, E. That Jazz! an Idiosyncratic Social History of the American Twenties. Nova York, Putnam's Sons, 1978.

REES, William (org.). French Poetry. Londres, Penguin, 1990.

SAHM, Estela (org.). Roberto Rodrigues 1906-1929 (Catálogo). São Paulo, A. S. Studio, 1993.

SCHWARTZ, Sanford. The Matrix of Modernism, Pound, Eliot and Early 20th Century Thought.

Princeton, University Press, 1985.

SEVCENKO, Nicolau. Orfeu Extático na Metrópole. São Paulo, Sociedade e Cultura nos Frementes

Anos 20. São Paulo, Companhia das Letras, 1992.

SILKIN, Jon (org.). First World War Poetry. Londres, Penguin, 1981.

SILLARS, Stuart. Art and Survival in First World War. Nova York, St. Martin's Press, 1987.

TIMMS, E. e KELLEY, D. (orgs.). Unreal City, Urban Experience in Modern European Literature and Art. Nova York, St. Martin's Press, 1985.

VALÉRY, Paul. Poésie. Milão, Feltrinelli, 1978.

WILLET, John. The New Sobriety, 1917-1933, Art and Politics in the Weimar Period. Londres,

Thames and Hudson, 1978.

WOHL, Robert. The Generation of 1914. Londres, Weinfeld and Nicolson, 1980.

YEATS, W. B. Selected Poetry. Harmondsworth, Penguin, 1991. 